J. Dairy Sci. 99:3217-3228

http://dx.doi.org/10.3168/jds.2015-10369

(C) American Dairy Science Association ${ }^{\circledR}, 2016$.

\title{
Social stressors and their effects on immunity and health of periparturient dairy cows ${ }^{1}$
}

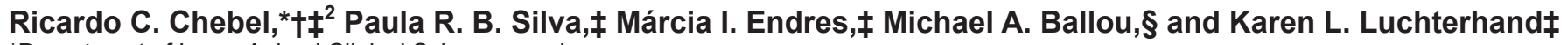 \\ *Department of Large Animal Clinical Sciences, and \\ †Department of Animal Sciences, University of Florida, Gainesville 32608 \\ łDepartment of Animal Sciences, University of Minnesota, St. Paul 55108 \\ §Department of Animal and Food Sciences, Texas Tech University, Lubbock 79409
}

\begin{abstract}
Management practices during the periparturient period have been the focus of much research recently because during this period immune function, metabolism, and health of cows are severely challenged. Responses to stress are often classified as behavioral, immunological, neuroendocrine, and autonomic. In production systems, understanding all facets of stress response is important to correctly predict the consequences of stressors to the health and performance of animals and to prevent costly managerial changes that have minimal effect on animal well-being and performance. Common social stressors faced by periparturient animals are regrouping, overstocking, and for nulliparous animals, commingling with parous animals. In conventional dairies, feeding strategies during the periparturient period often require several group changes during the most challenging period of an animal's life. Traditional weekly regrouping of prepartum cows increases competitive behavior at the feed bunk but it does not affect immune and metabolic responses, health and production, as long as stocking density is not overwhelming, and nulliparous and parous animals are housed separately. Stocking density of prepartum animals may be overlooked because these are nonproductive animals. Severe overstocking (200\% of feeding space) of commingled nulliparous and parous pregnant animals produces neuroendocrine and metabolic changes. On the other hand, when prepartum nulliparous and parous animals are housed separately, stocking densities of up to $120 \%$ do not seem to affect innate and adaptive immunity, metabolic responses, milk yield, and reproduc-
\end{abstract}

\footnotetext{
Received September 8, 2015.

Accepted December 19, 2015.

${ }^{1}$ Presented as part of the Animal Health: Understanding and Reducing the Impact of Various Stressors on Immune Responses and Health of Cattle Symposium at the ADSA-ASAS Joint Annual Meeting, Orlando, Florida, July 2015.

${ }^{2}$ Corresponding author: rcchebel@ufl.edu
}

tive performance, despite increasing negative behavior among cows. In recent experiments, when animals were ranked based on feed bunk displacement, dominant animals were more likely to be diagnosed with metritis than subordinate animals. Importantly, dominant animals with large number of interactions with pen mates (displacement at the feed bunk) were considerably more likely to be diagnosed with uterine diseases (retained placenta and metritis) and to be removed from the herd within $60 \mathrm{~d}$ postpartum. Much has been learned about behavioral responses of cows to stressful conditions, but our understanding of neuroendocrine and immune responses to such conditions is somewhat limited. A multidisciplinary approach to research that encompasses several responses to stress and biological functions is critical.

Key words: periparturient cow, social stressor, immune function, health

\section{INTRODUCTION}

Stress has many definitions, etiologies, and consequences that are not necessarily identical to all animals or to all stressors. Once a stressor is identified, the body organizes a biological response that, according to the stressor, may be autonomic, neuroendocrine, immune, or behavioral or a combination of them (Moberg, 2000). Often biological responses to stress are sufficient to eliminate the stressor without significant alterations to the biological functions of the animal. Severe or chronic stress, however, may be of sufficient magnitude to produce biological responses that alter biological functions, disrupt homeostasis, predispose the animal to pathological conditions, and cause pathologies (Moberg, 2000). Autonomic response (fight or flight response) is short lived, involves the cardiovascular and gastrointestinal systems and the adrenal and exocrine glands, and has minimal effect on the biological function of animals that survive the stressor (Elsasser et al., 2000). Neuroendocrine responses, which involve the hypothalamus-pituitary-adrenal axis, may result in 
significant changes to the secretion of glucocorticoid, prolactin, somatotropin, thyroid stimulating hormone, LH, and FSH and are believed to have a profound effect on immune and metabolic functions (Elsasser et al., 2000). Innate and adaptive immune responses to a stressor are mounted depending on the etiology and immunogenicity of the pathogen (Elsasser et al., 2000). Nonpathogenic stressors, however, may have a direct (i.e., malnutrition, heat stress) or indirect (i.e., through glucocorticoids and somatotropin) effect on immune function (Elsasser et al., 2000). Finally, the behavioral response is mounted once a perceived threat to homeostasis is identified (Elsasser et al., 2000). For example, an animal exposed to heat stress seeks shade and water to reduce body temperature (Kendall et al., 2006), whereas a submissive animal avoids the feed bunk while more dominant animals are feeding (Friend and Polan, 1974).

Although one may argue that stress and biological responses to stress have little relevance if no consequences to biological functions of the animals are observed, this mindset is not acceptable to some consumers in most developed countries or by the scientific community because of ethical considerations. On the other hand, many experiments have focused on one biological response to stress (i.e., behavior) but were not necessarily designed to evaluate other biological responses to stress and their consequences to the biological function of the animals. As we increasingly attempt to improve wellbeing of animals through proper managerial strategies, while maintaining sustainability of food-producing industries, a holistic approach must be taken and evaluation of biological responses to stress, biological function, incidence of pathological conditions, and mortality must occur. Affective state is another area of importance to the evaluation of animal well-being. Although it is often counterintuitive to consider that animal feelings can be evaluated, researchers have been working on developing reliable measures of affective state (e.g., pain, fear, pleasure, preference). In general, such evaluations are based on what are believed to be responses associated with the affective state that the animal is in. Perception of pain, for example, may be evaluated by a wide range of techniques such as thermal, electrical, and mechanical stimuli (Melia et al., 2015). Pressure algometry appears to be a more objective method for evaluation of pain (Melia et al., 2015) and has been used to measure efficacy of therapeutic interventions for pain prevention and treatment (Stock et al., 2015). In experimental herds, it is possible to conduct experiments to determine the preference of cows to different management conditions (e.g., access to pasture; Legrand et al., 2009) and facilities (e.g., freestall design; Abade et al., 2015).

It has been suggested that natural behaviors of dairy cows such as resting, feeding, and rumination are associated with health, welfare, and productivity (Grant, 2007). Situations of limited space, limited feed, elevated stocking density, and frequent regrouping (physically moving cows from pen to pen) may increase the competition for resources, limit cows' ability to behave naturally, and increase expression of aggressive behaviors (Friend and Polan, 1974; Wechsler, 2007). Although the focus of this review is not the consequences of social stressors on behavior, behavioral responses may directly or indirectly affect immune status, and the animal's response to social stressors is often behavioral in nature (e.g., altered feeding behavior of a subordinate cow).

The effects of limited access to resources and social stressors on immune function, metabolic status, health, and performance of dairy cattle are less understood. However, if situations of social stress result in changes in feeding behavior and reduced DMI, such stressors may exacerbate negative energy balance during the periparturient period and predispose dairy cows to immunosuppression, metabolic disorders, and diseases. Therefore, a comprehensive review of the consequences of social stressors to immune function and health must also take into consideration behavioral responses and their consequences.

\section{Stocking Density in the Periparturient Period}

To increase herd size without increasing investments in facilities, many dairy farms chose to overstock (Bewley et al., 2001), particularly during the prepartum period. Grant and Albright (2001) suggested that housing a greater number of cows than the number of stalls available or decreasing the linear feeding space to $<60 \mathrm{~cm}$ per cow characterizes overstocking. On the other hand, the Canadian Code of Practice for Dairy Cattle (DFC-NFACC, 2009) suggests that decreasing the linear feeding space to $<76 \mathrm{~cm}$ per prepartum cow characterizes overstocking (DFC-NFACC, 2009). Many believe that overstocking can be overcome by dairy animals when feed is available $24 \mathrm{~h}$ per day because there would be constant rotation of animals eating, drinking, and resting. Dairy animals, however, present allelomimetic behavior and typically $80 \%$ of headlocks are occupied at peak feeding time, after fresh feed delivery, and animals that do not have access to fresh feed do not return to the feed bunk when their pen mates are not feeding (Nordlund et al., 2006). Huzzey et al. (2006) demonstrated that, following fresh feed delivery, 
approximately $80 \%$ of cows were at the headlock when they were housed in pens with 1.33 and 1 headlock/ cow. On the other hand, when stocking density was increased (0.33 and 0.67 headlock/cow), approximately 30 to $50 \%$ of cows were at the headlock following fresh feed delivery. The percentage of cows at the headlock between feedings was not different when cows were housed at 0.33 to 1.33 headlock/cow, demonstrating that limited access to fresh feed is not overcome by visits to the feed bunk between feedings.

Several researchers have evaluated the consequences of overstocking on behavior of lactating and peripartum (immediate prepartum and postpartum periods) dairy animals. A linear reduction in lying time was observed when stocking density increased from 100 to $150 \%$ of stalls (109, 120, 133, and 150\%; Fregonesi et al., 2007). The lying time and the percentage of cows eating upon return from the milking parlor decreased and the percentage of cows standing idly waiting for access to stalls increased when stocking density exceeded $113 \%$ (113, 131 , and $142 \%$ of stalls and headlocks; Hill et al., 2009). Furthermore, the number of displacement events from the feed bunk increased linearly according to increase in stall stocking density (100, 113, 131, and 142\%; Krawczel et al., 2012). On the other hand, increase in feed bunk space from 51 to $102 \mathrm{~cm}$ per cow reduced the number of aggressive interactions and increased the percentage of cows feeding during the 90 min following feed delivery (DeVries et al., 2004), whereas decreasing feed bunk space from 81 to $21 \mathrm{~cm}$ caused a reduction in feeding time and an increase in aggressive behavior (Huzzey et al., 2006). Reduced feeding space resulted in greater standing time idly waiting for access to feed (Singh et al., 1993; Olofsson, 1999; Huzzey et al., 2006). The increased standing time of animals exposed to overstocking has been suggested to be detrimental to hoof health and increase the incidence of lameness because of the strain on the hoof from standing on concrete flooring (Cook, 2002) and because of the softening of the hoof of cows that stand longer on manure-covered alleyways (Guard, 2002). Hetti Arachchige et al. (2014) evaluated behavior of grazing lactating dairy cows that were offered a supplemental TMR with different feeding space allowance. Cows were on pasture for approximately $19 \mathrm{~h}$ per day, and approximately $30 \%$ of their daily DMI was from perennial ryegrass. Rolled wheat grain offered during milking accounted for $17.5 \%$ of their daily DMI. The remaining $52.5 \%$ of their daily DMI was offered in the form of a TMR in feeding spaces of $0.6,0.75$, and $1.0 \mathrm{~m}$ per cow. As described previously in confined dairy cattle, reducing feeding space allowance from 1.0 to $0.6 \mathrm{~m}$ per cow reduced the number of feeding bouts and feeding bout length and resulted in more variability in individual animal feeding time. Subordinate cows, however, had the greatest reduction in feeding time when feeding space allowance was reduced from 1.0 to $0.6 \mathrm{~m}$ per cow. One may conclude, therefore, that competition in the feed bunk is observed when feeding space allowance is reduced in confined and semi-confined systems.

Few experiments have demonstrated a link between feeding and resting space allowance and biological responses beyond behavior. Sova et al. (2013) evaluated nutritional and management conditions associated with productivity of dairy cows in 22 herds in Canada. In this experiment, greater feed bunk space (range $=0.36$ to $0.99 \mathrm{~m} / \mathrm{cow}$ ) was associated with reduced SCC and greater milk fat content, whereas greater linear water space (range $=3.8$ to $11.7 \mathrm{~cm} / \mathrm{cow}$ ) was associated with reduced MUN and greater test day milk yield, but reduced milk protein content. In another experiment with dairy herds using automated milking systems, the same group demonstrated that feed bunk space (range $=0.3$ to $1.0 \mathrm{~m} / \mathrm{cow}$ ) was positively associated with milk yield (Deming et al., 2013). These experiments (Sova et al., 2013; Deming et al., 2013), however, are epidemiological in nature and causality cannot be inferred. Munksgaard and Simonsen (1996) demonstrated that blood cortisol blood concentrations, an indicator of stress associated with immunosuppression, was increased among cows deprived of lying space.

Hosseinkhani et al. (2008) demonstrated that overstocking (ratio of cows to feeding bin was 2:1 vs. 1:1) prepartum dairy cows resulted in increased feeding rate, meal duration, and meal size, whereas meal frequency was reduced. In a similar experiment, overstocking primiparous cows resulted in increased time not eating within a meal prepartum and increased meal time pre- and postpartum (Proudfoot et al., 2009). On the other hand, overstocking multiparous cows resulted in reduced visit intake and daily feed intake prepartum, reduced visit feed time pre- and postpartum, increased feeding rate postpartum, and reduced daily feed time postpartum. Primiparous and multiparous cows had greater displacement rate from the feed bunk when housed in overstocked conditions (Proudfoot et al., 2009). Huzzey et al. (2012) demonstrated that nulliparous animals commingled with parous animals and housed in pens with $200 \%$ stocking density (animals per headlocks) had reduced feeding time, had increased interval to approach the feed bunk, had increased plasma nonesterified fatty acids (NEFA), plasma glucose, and fecal cortisol concentrations, and were more resistant to insulin than nulliparous animals commingled with parous animals and housed at $100 \%$ stocking density (Huzzey et al., 2012). On the other hand, parous ani- 
mals commingled with nulliparous animals and housed at $200 \%$ stocking density had minimal alterations in behavior, had slightly increased NEFA concentrations, and had decreased sensitivity to insulin compared with parous animals housed at $100 \%$ stocking density (Huzzey et al., 2012). In that experiment, cows were approximately $30 \mathrm{~d}$ from calving at enrollment and immune function and health and productive responses were not evaluated.

Effects of stocking density and social stressors on milk yield are not evident (Krawczel et al., 2008; Hill et al., 2009), but the importance of stocking density to productive performance may not be completely discounted because many experiments had an insufficient number of animals to evaluate such response and some exposed cows to overstocking for a short period of time. Milk fat percentage was reduced by approximately 0.2 percentage points at $142 \%$ stocking density (stalls and headlocks) compared with $100 \%$ stocking density, and SCC tended to increase for stocking densities above 113\% (Krawczel et al., 2008). Oetzel et al. (2007) evaluated the association between stocking density (range $=62$ to $138 \%$ of stalls) in prepartum pens of commingled nulliparous and parous animals and milk yield. Milk yield of primiparous animals (nulliparous animals that had been commingled with parous animals in the prepartum period) decreased by $0.7 \mathrm{~kg} / \mathrm{d}$ from 3 to 85 DIM for every 10-percentage-unit increase in prepartum stocking density above $80 \%$. The experiment, however, was designed to evaluate feed additives in the prepartum period and stocking density data were collected a posteriori. Consequently, variations in stocking density during the experiment likely followed seasonality in calving observed in many large dairy herds.

The effects of overstocking on immune status and health of periparturient animals are not well understood. Dairy ewes housed in high $\left(1.5 \mathrm{~m}^{2} /\right.$ ewe $)$ stocking density from late gestation to mid lactation had reduced anti-ovalbumin IgG concentration in response to an ovalbumin challenge compared with ewes housed in low (3 $\mathrm{m}^{2}$ /ewe) stocking density (Caroprese et al., 2009). Furthermore, ewes that were housed in high-stockingdensity conditions tended to have greater number of aggressive interactions, had reduced milk yield, and had increased milk SCC (Caroprese et al., 2009). In a recent experiment, effects of increasing prepartum stocking density from 80 to $100 \%$ of headlocks during the last $35 \mathrm{~d}$ of gestation on behavior, immune and metabolic status, and performance of Jersey animals were evaluated. To maintain a semi-constant stocking density close to the desired 80 and $100 \%$ stocking densities, new cows were moved to the prepartum pens twice a week as necessary. The mean $( \pm$ SEM) stock- ing densities during the prepartum period were $74.1 \pm$ $0.4 \%$ versus $94.5 \pm 0.3 \%$ of headlocks and $80.8 \pm 0.4 \%$ versus $103.1 \pm 0.4 \%$ of stalls. The number of displacements from the feed bunk per day increased throughout the prepartum period and daily lying time decreased in the last $7 \mathrm{~d}$ prepartum in the pens with $100 \%$ stocking density (Lobeck-Luchterhand et al., 2015). Effects of stocking density on daily feeding time were contradictory as parous animals housed at $100 \%$ stocking density had reduced feeding time $(7.6 \mathrm{~min} / \mathrm{d}$ less $)$, whereas nulliparous animals housed at $80 \%$ stocking density had reduced feeding (12.4 min/d less; Lobeck-Luchterhand et al., 2015). Despite the negative effects of increased stocking density on behavioral responses of prepartum animals, increasing stocking density from 80 to $100 \%$ had no effect on responses associated with innate and adaptive immune function, metabolic status, stress measured by blood and hair cortisol concentrations, and systemic inflammation (Silva et al., 2016). Furthermore, housing nulliparous and parous animals at 80 versus $100 \%$ stocking density did not affect incidence of uterine (retained placenta, metritis, and purulent vaginal discharge) and metabolic (ketosis and displacement of abomasum) diseases and productive and reproductive performance (Silva et al., 2014). It is important to note that in this experiment (Silva et al., 2014, 2016; Lobeck-Luchterhand et al., 2015) nulliparous and parous animals were housed separately during the prepartum period. More recently, Miltenburg (2015) evaluated the consequences of stocking density ( 80 vs. $120 \%$ stall stocking density and 90 vs. $45 \mathrm{~cm}$ of feedbunk space) on behavior, immune, metabolic, and productive responses of parous Holstein animals. Greater stocking density resulted in fewer hours lying down per day and greater number of displacements from the feedbunk (Miltenburg, 2015). Increasing stocking density of prepartum Holstein cows slightly increased the hepatic concentration of triacylglycerol during the postpartum period but stocking density did not affect other metabolic responses, immune response, uterine health, and milk yield (Miltenburg, 2015). One may argue that in these experiments (Lobeck-Luchterhand et al., 2015; Miltenburg, 2015; Silva et al., 2014, 2016) overstocking was not dramatic enough to result in biological responses to stress and alterations in biological function. Nonetheless, the results of these experiments suggest that the links between behavioral responses and immune function, metabolic status, and performance of periparturient dairy cows need to be investigated in controlled experiments that apply higher stocking densities.

Unquestionably, overstocking the feed bunk results in considerable behavioral changes, but it is still not clear what overstocking threshold must be achieved for 
DMI, metabolism, and immunity to deteriorate consistently. It is important to note that different levels of overstocking may have different effects on animal response depending on other variables such as availability of water, heat stress, poor comfort, and stressful handling, to cite a few. Because reproductive performance in many dairy herds is seasonal (Hansen, 2009), with reduced fertility during the warmer months and improved fertility during the cooler months of the year, often a disproportionate number of calving occurs during the summer months. Therefore, once the "ideal" stocking density is determined, facilities must be built to meet such requirements during the time when most calving occurs.

\section{Regrouping of Periparturient Dairy Cows}

In dairy operations of all sizes, animals are often regrouped to facilitate management. Grouping strategies are generally based on nutritional requirements, pregnancy status, and stage of gestation. During the transition from lactation to late gestation/dry period to lactation, cows are often physically moved to new pens 3 to 6 times. In most herds, cows are moved from a milking cow pen to a far-off dry cow pen at approximately $220 \mathrm{~d}$ of gestation, from the far-off dry cow pen to a close-up dry cow pen at approximately $250 \mathrm{~d}$ of gestation, from the close-up dry cow pen to a maternity pen at calving, from the maternity pen to a hospital pen within 2 to $12 \mathrm{~h}$ after calving, from the hospital pen to a postpartum cow pen within $48 \mathrm{~h}$ after calving, and from the postpartum cow pen to a milking or breeding pen at approximately 21 DIM. These changes are important to optimize nutrition and management tasks such as health monitoring and breeding. Aside from the physical move, cows often face entrance of new cows in the group on a weekly basis.

Following regrouping, cows reestablish hierarchical order (social ranks) through physical and nonphysical interactions, which may exacerbate expression of aggressive and submissive behaviors (Kondo and Hurnik, 1990). Social stability, establishment of social ranks, and return of frequency of interactions to preregrouping levels are usually observed within 3 to 5 $\mathrm{d}$ of regrouping and usually no more than 7 to $14 \mathrm{~d}$ after regrouping (Grant and Albright, 1995, 2001). In a study with lactating dairy cows, changes in feeding and resting behavior and reduced milk yield following regrouping only lasted for 24 to $48 \mathrm{~h}$ (von Keyserlingk et al., 2008). Therefore, the interval from regrouping to social stability is likely dependent on animal characteristics, availability of resources (feed, water, and resting space), and likely the number of cows moved.
The experiments cited herein moved a small number of animals, whereas in commercial dairies a larger number of cows are moved together and it is unclear whether this practice eliminates some of the negative effects of cow movement cited previously.

Most experiments have evaluated the consequences of regrouping on behavior and, less frequently, on neuroendocrine responses and biological function. Hasegawa et al. (1997) demonstrated that regrouping of mid-lactation primiparous animals resulted in reduced milk yield, particularly for mid-ranking and lowranking animals, but regrouping did not affect blood cortisol concentrations. von Keyserlingk et al. (2008) demonstrated that regrouped lactating dairy cows had reduced feeding time (15 fewer minutes in the first day after regrouping) and resting time (3 fewer hours in the first day after regrouping), were displaced from the feed bunk more often following regrouping (approximately 2.5 -fold increase in displacement on the day of and on the day after regrouping), and had reduced milk yield (approximately 4 fewer $\mathrm{kg}$ on the day of regrouping).

Reduced DMI of periparturient dairy animals in the last days before calving predisposes them to negative energy balance, immunosuppression, and metritis (Goff and Horst, 1993; Hammon et al., 2006; Huzzey et al., 2007). Therefore, if constant regrouping of prepartum dairy animal exacerbates the reduction in DMI observed in the last days of gestation, it is logical to argue that constant regrouping could affect immune function and health of periparturient dairy cows. Schirmann et al. (2011) demonstrated that prepartum cows moved to a different pen had reduced DMI on the day following movement (1.3 fewer $\mathrm{kg}$ ) but DMI returned to pre-moving levels by d 1 after movement. On the other hand, rate of intake was reduced ( 5 to $7 \mathrm{~g} / \mathrm{min}$ slower) from the day of the movement to $2 \mathrm{~d}$ after movement among cows that were physically moved and cows that remained in the pen and received new pen mates. Surprisingly, cows that were physically moved to a new pen initiated more displacements at the feed bunk on the day after movement than cows that remained in the same pen (Schirmann et al., 2011). Taking into consideration the effects of regrouping on behavioral changes, feed intake, and milk yield of lactating dairy cows, some have suggested that a stable prepartum pen (no regrouping of animals in the last $28 \mathrm{~d}$ of gestation) would improve health and productivity during the postpartum period. Coonen et al. (2011) demonstrated that Holstein cows housed in a stable pen with no entry of new cows in the prepartum period (during the last 14 to 28 d before calving) had similar DMI and NEFA concentration during the prepartum period and had similar milk yield in the first 30 DIM compared with 
cows housed in pens with entry of new cows twice weekly in the last 14 to $28 \mathrm{~d}$ before expected calving date. This experiment, however, had insufficient number of cows to evaluate the effects of stable prepartum groups on health and reproductive performance. In an experiment conducted in a commercial dairy herd, researchers evaluated whether a stable group during the prepartum period would improve responses associated with behavior, immune and metabolic status, and performance of Jersey cows (Silva et al., 2013a,b; Lobeck-Luchterhand et al., 2014). Although the number of displacements from the feed bunk per cow per day was reduced in the stable pen, no differences were found in feeding time during the last $3 \mathrm{wk}$ of gestation and in percentage of cows feeding throughout the day between the stable and weekly regrouping strategy (Lobeck-Luchterhand et al., 2014). Because this experiment was conducted in a large commercial herd, it was not possible to compare DMI of cows in the stable and weekly regrouping strategy. Concentrations of NEFA and glucose during the periparturient period and BHB during the postpartum period, BCS from $21 \mathrm{~d}$ before to $56 \mathrm{~d}$ after calving, and yield of ECM were not affected by grouping strategy, leading to the conclusion that a stable group did not improve energy status of periparturient cows (Silva et al., 2013a,b). A sub-group of cows from this experiment was evaluated for neuroendocrine response (blood cortisol) and innate and adaptive immune responses during the periparturient period (Silva et al., 2013b). Cows housed in the stable group had reduced blood cortisol concentration $7 \mathrm{~d}$ before calving, but grouping strategies had no effect on innate and adaptive immune responses. Finally, providing a stable group throughout the prepartum period did not reduce the incidence of health disorders, did not improve milk yield, and did not affect reproductive performance (Silva et al., 2013a). This leads to the conclusion that weekly or twice weekly regrouping of prepartum cows, when access to feed, water, and resting space is sufficient to minimize competition among cows, does not affect immune function, metabolic status, and performance. Considering that the stable group strategy reduced the use of prepartum facilities (stocking density reduced from 86.9 to $71.9 \%$; Silva et al., 2013a), it seems illogical to recommend such strategy in light of the costs to build transition cow facilities.

\section{Association Among Social Rank, Health, and Performance}

Social dominance is observed when a subordinate animal yields space to a dominant animal because of threat or force. Based on experiments with turkeys, so- cial rank models described a linear relationship among animals (e.g., animal 1 would dominate all others, animal 2 would dominate all others but animal 1, animal 3 would dominate all others but animals 1 and 2 , and so forth). More recently, however, it has been established that more complex nonlinear relationships may occur, which is believed to be the case among dairy cattle. Although it is generally accepted that social rank is dependent on size, BCS (Hohenbrink and MeineckeTillmann, 2012), and age, smaller and younger animals within a group may also be dominant.

It is generally believed that high-ranking animals have fewer diseases and have better performance because they would more easily gain access to resources during situations of competition. In fact, incidence of murine virus-induced leukemia was affected by social rank as higher-ranking mice were less likely to develop it (Ebbesen et al., 1991). Pigs classified as high ranking according to their ability to win interactions at feeding time challenged with Aujeszky disease virus had improved immune response and reduced morbidity and mortality compared with middle- and low-ranking pigs (Hessing et al., 1994). In another experiment, immune response of 12-wk-old pigs that were mixed with unfamiliar pigs and exposed to reduced access to feed (pig to feed place ratio $=2.25: 1$ ) were evaluated (Tuchscherer et al., 1998). Competition among pigs at feeding was evaluated and pigs were classified as subordinate and dominant (based on dominance value = wins-defeats / number of agonistic interactions) and numbers of agonistic interactions in which pigs were involved were recorded. In vitro lymphocyte proliferation responses to concanavalin A, phytohemagglutinin, and pokeweed were increased in dominant pigs $3 \mathrm{~d}$ after regrouping compared with subordinate pigs, whereas blood cortisol concentration was greater among subordinate pigs $1 \mathrm{~d}$ before regrouping. Change in concanavalin A stimulated lymphocyte proliferation from $1 \mathrm{~d}$ before regrouping to $3 \mathrm{~d}$ after regrouping was dependent on dominance value and number of agonistic interactions pigs participated in, such that dominant pigs involved in a large number of agonistic interactions had the greatest increase in lymphocyte proliferation (Tuchscherer et al., 1998).

Although dominance rank tends to be stable for highand low-ranking cows, rank of middle-ranking cows fluctuates according to availability of resources and regrouping (Arave and Albright, 1976). Although among indoor-housed dairy cows dominance over 3 different resources (feed, stalls, and brush) is not correlated, $88 \%$ of displacements occurred at the feed bunk (ValLaillet et al., 2008). As it relates to immune function, health, and performance, gaining access to feed and water is likely the most important parameter to evalu- 
ate according to social rank. Within $2 \mathrm{~h}$ following fresh feed delivery, high-ranking cows spent more time at the feeder compared with low-ranking cows (Val-Laillet et al., 2008), which could potentially alter ingested feed because of sorting by dominant cows (Proudfoot et al., 2009). Arave and Albright (1976) demonstrated that milk yield of high-, middle-, and low-ranking cows decreased in the week following regrouping. Milk yield of middle- and low-ranking cows returned to pre-regrouping levels 2 wk after regrouping, whereas high-ranking cows continued to have lower milk yield 2 wk after regrouping compared with pre-regrouping levels (Arave and Albright, 1976). In an experiment in which the effects of regrouping on milk yield were evaluated, primiparous animals that remained in the pen from which animals were removed and rose in the social rank had reduced milk yield 1 wk after regrouping (Hasegawa et al., 1997). Dominant primiparous animals that were moved to a new pen had an increase in blood cortisol concentration, whereas blood cortisol concentration of mid-ranking and low-ranking animals did not change (Hasegawa et al., 1997). These findings lead to the question of whether social dominance necessarily means improved biological function or whether excessively aggressive animals may actually have compromised function.

In an attempt to standardize social ranking, Galindo and Broom (2000) suggested that cows should be classified according to displacement index [DI; number of times it displaces others/(number of times it displaces others + number of times it is displaced by others)] as low ranking $(\mathrm{DI}<0.4)$, middle ranking $(\mathrm{DI}=0.4$ to 0.6 ), and high ranking $(\mathrm{DI}>0.6)$. When prepartum nulliparous and parous animals were housed at $200 \%$ stocking density (0.34 $\mathrm{m}$ of feedbunk space and cow to stall ratio $=2: 1$ ) low-ranking animals had greater blood NEFA and fecal cortisol metabolite (11,17-dioxoandrostanes) concentrations compared with mid-ranking and highranking animals (Huzzey et al., 2012). Furthermore, low-ranking animals had greater insulin concentration in response to a glucose tolerance test than high-ranking cows (Huzzey et al., 2012). Although these findings may suggest that the rise in glucocorticoids in response to stress among low-ranking animals may predispose them to insulin resistance, a disproportionate number of nulliparous animals were classified as low ranking compared with parous animals and may have resulted in confounding effect. Lobeck-Luchterhand (2014) demonstrated that multiparous high-ranking Jersey cows had lower NEFA concentration at parturition than lowranking cows, whereas primiparous high-ranking Jersey cows had greater NEFA concentration than middleranking and low-ranking cows.
With few exceptions, the numbers of animals used in experiments in which social rank was determined are often small, precluding conclusions regarding the association between social rank and immune function, health, and performance. In recent experiments in which prepartum management strategies (different stocking density and stable group) were evaluated, behavior of 953 Jersey animals was monitored allowing for the calculation of DI and evaluation of the association between social rank and metabolic responses, health, and performance (Lobeck-Luchterhand, 2014). Furthermore, in a sub-sample $(\mathrm{n}=94)$ of these animals, innate and adaptive immune responses as well as inflammatory response and hemogram parameters were evaluated (R. Chebel, P. Silva, M. Endres, and K. Lobeck, unpublished data). To investigate the association between DI and immune responses, cows were classified as being in the top 10th percentile of DI, bottom 10th percentile of DI, and middle DI (remaining $80 \%$ ) without taking into consideration the number of agonistic interactions in which cows were involved because of the reduced number of animals. Intensity of oxidative burst (Figure 1A) and phagocytosis (Figure 1B) by polymorphonuclear leukocytes was associated with class of DI. Animals in the top 10th percentile of DI had greater intensity of phagocytosis and oxidative burst than animals in the bottom 10th percentile and middle DI, particularly on the day of calving. These findings are corroborated by Miltenburg (2015) who demonstrated that high-ranking Holstein cows had greater increase in oxidative burst during the periparturient period compared with low-ranking cows. When Jersey animals were classified according to social rank as suggested by Galindo and Broom (2000), an association between social rank and incidence of retained fetal membranes was observed (Lobeck-Luchterhand, 2014). Surprisingly, high-ranking cows were almost twice as likely to have retained fetal membranes compared with low-ranking animals (adjusted odds ratio $=1.99 ; 95 \% \mathrm{CI}=1.08,3.70)$, whereas no differences were found in likelihood of retained fetal membranes between middle-ranking and low-ranking animals and between middle-ranking and high-ranking animals. No differences in incidence of metritis, acute metritis, endometritis, ketosis, mastitis, and lameness (at 1, 35, and 56 DIM) were observed among animals of different social ranks. On the other hand, milk yield during the first 80 DIM of high-ranking cows ( $\geq$ third lactation) was 3 to $7 \mathrm{~kg} / \mathrm{d}$ greater than low-ranking cows, but no differences in milk yield according to social rank were observed among first- and second-lactation cows. To further investigate the association between feed bunk behavior and health, Lobeck-Luchterhand (2014) evalu- 
ated the probability of uterine diseases (retained fetal membranes and metritis) and removal from the herd within 60 DIM according to DI and number of agonistic interactions in which cows were involved. An inverse relationship was found between DI and probability of uterine diseases and removal from the herd within 60 DIM. Similarly, the number of agonistic interactions in which a cow was involved was inversely related to the probability of uterine diseases and removal from the herd within 60 DIM. Interestingly, the interaction between DI and number of agonistic interactions in which a cow was involved also was associated with probability of uterine diseases (Figure 2A) and removal from the herd (Figure 2B). According to these data, a cow with high DI and high number of agonistic interactions had the greatest likelihood of uterine diseases and removal from the herd within 60 DIM. Based on these data, we can hypothesize that dominance may be detrimental to cows that are naturally aggressive and seek to assert their dominance at the feed bunk instead of gaining access to feed and water for their intake. These findings contrast with the findings by Huzzey et al. (2007) and Patbandha et al. (2012) who demonstrated that cows diagnosed with metritis were less aggressive at the time of feeding (less likely to displace pen mates and more likely to be displaced by pen mates) than cows that were not diagnosed with metritis. Similarly, cows diagnosed with subclinical ketosis initiated fewer displacements at the feed bunk during the week before calving compared with healthy cows (Goldhawk et al., 2009).

Experiments evaluating the consequences of social interaction and social rank on immune, metabolic and health responses have produced inconsistent results often because of insufficient number of animals, inconsistencies in management strategies (e.g., stocking density, availability of resources), differences in periods during which behavior was evaluated, breed, and pre-existing conditions that may affect behavior and likelihood of diseases. Proudfoot et al. (2014) demonstrated that sick periparturient cows ate less, tended to spend more time lying down, and spent more time in the corner of the pen compared with healthy cows. Acute bacterial, protozoan, or viral infections produce nonspecific symptoms such as pyrexia, uneasiness, loss of interest for daily activities, and anorexia (Aubert, 1999). The cross-talk between neuroendocrine and immune systems has been demonstrated in all forms of life, indicating that behavioral and immune responses act synergistically to fight infections (Aubert, 1999; McEwen, 2000, 2008). Calm bulls had smaller increase in cortisol concentration $24 \mathrm{~h}$ after transportation compared with temperamental bulls (Hulbert et al.,
2011). Although polymorphonuclear leukocyte activity was reduced by $48 \mathrm{~h}$ after transportation in calm and temperamental bulls, polymorphonuclear leukocyte activity of calm bulls was greater at $96 \mathrm{~h}$ after transportation than during the pre-transportation period, whereas temperamental bulls had only slight increases in polymorphonuclear leukocyte activity by $96 \mathrm{~h}$ (Hulbert et al., 2011). Continuous (24 h per day) exposure of male rats to adult fight-experienced male rats caused a reduction in the concentration of CD4 $\mathrm{T}$ helper and
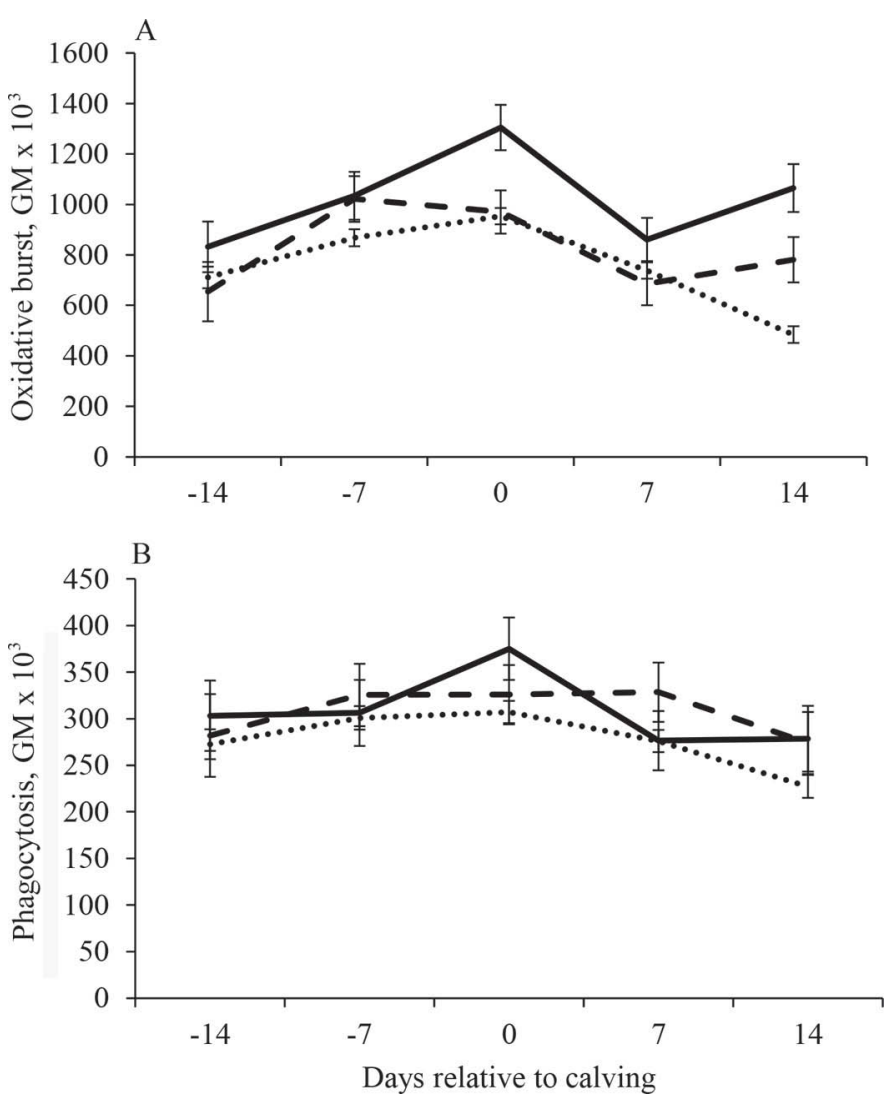

Figure 1. (A) Association between social rank and intensity of oxidative burst by polymorphonuclear leukocytes $(\mathrm{GM}=$ geometric mean; error bars $=\mathrm{SEM})$. Solid line $=$ top 10 percentile; dotted line $=$ middle ranking cows; and dashed line $=$ bottom 10 percentile. Rank determined according to displacement index (number of times a cow displaces others/(number of times a cow displaces others + number of times a cow is displaced by others). Effect of rank, $P=0.01$; day relative to calving, $P<0.01$; and the interaction between rank and day relative to calving, $P=0.37$. (B) Association between social rank and intensity of phagocytosis by polymorphonuclear leukocytes (GM $=$ geometric mean; error bars $=\mathrm{SEM})$. Solid line $=$ top 10 percentile; dotted line $=$ middle ranking cows; and dashed line $=$ bottom 10 percentile. Rank determined according to displacement index (number of times a cow displaces others/(number of times a cow displaces others + number of times a cow is displaced by others). Effect of rank, $P=$ 0.05 ; day relative to calving, $P<0.01$; and the interaction between rank and day relative to calving, $P=0.63$. 

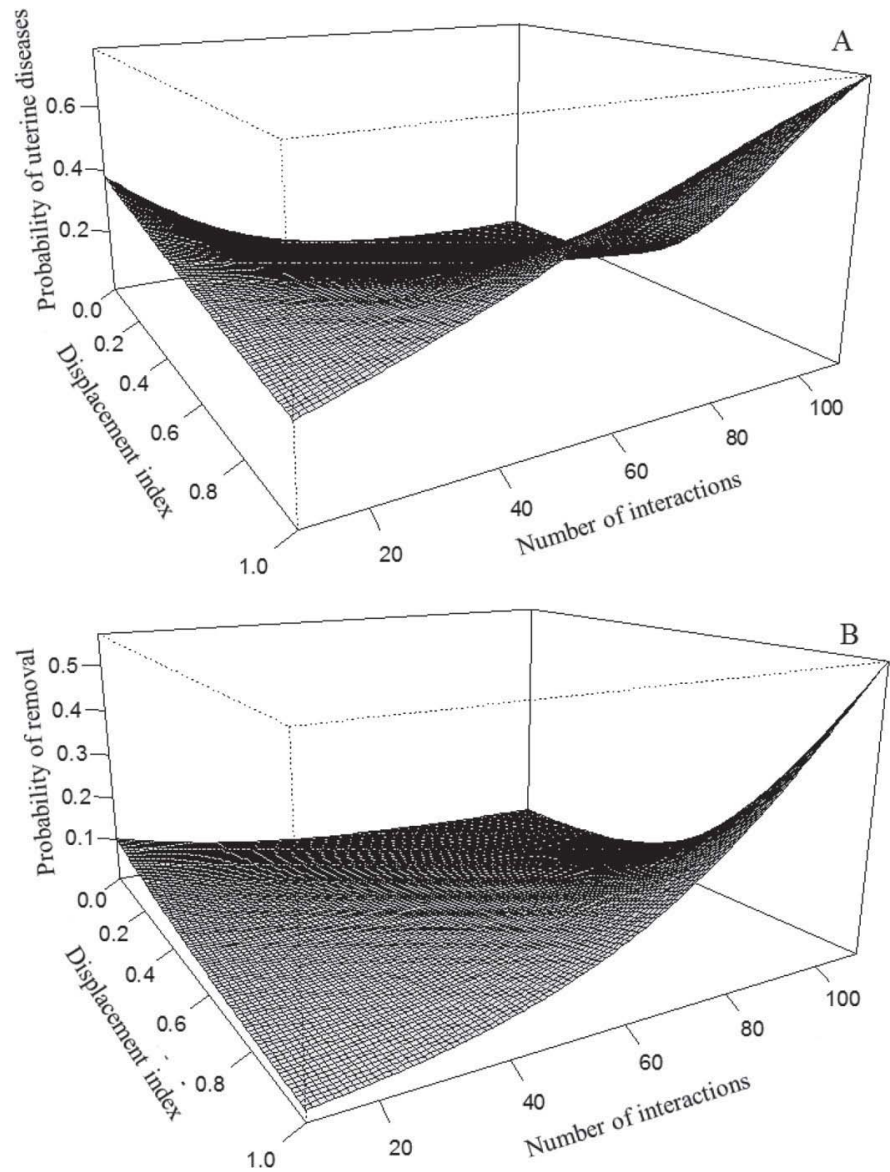

Figure 2. (A) Association among displacement index, number of interactions in which a cow is involved, and probability of postpartum uterine disease (retained fetal membrane, metritis, or both) among primiparous animals. Probability of health disorder increases among cows that have high displacement index and are involved in a large number of interactions (adapted from data in Lobeck-Luchterhand, 2014). (B) Association among displacement index, number of interactions in which a cow is involved, and probability of removal from the herd within 60 DIM (primiparous and multiparous cows). Probability of removal from the herd within 60 DIM increases among cows that have a high displacement index and are involved in a large number of interactions (adapted from data in Lobeck-Luchterhand, 2014).

CD8 T cytotoxic cells compared with male rats transiently ( $4 \mathrm{~h}$ per day) exposed to adult fight-experienced male rats (Stefanski et al., 2013). Haskell et al. (2014) indicated that several behavioral responses in dairy and beef cattle have moderate to high heritability. Thus, identification of gene haplotypes associated with temperament and behavior may prove important for the selection of cattle.

Based on the evidence presented herein, we hypothesize that social dominance may not necessarily lead to improved immune function, health, and performance in situations of competition for resources. Actually, we suggest that submissive animals may even have greater success than aggressive animals when the former con-
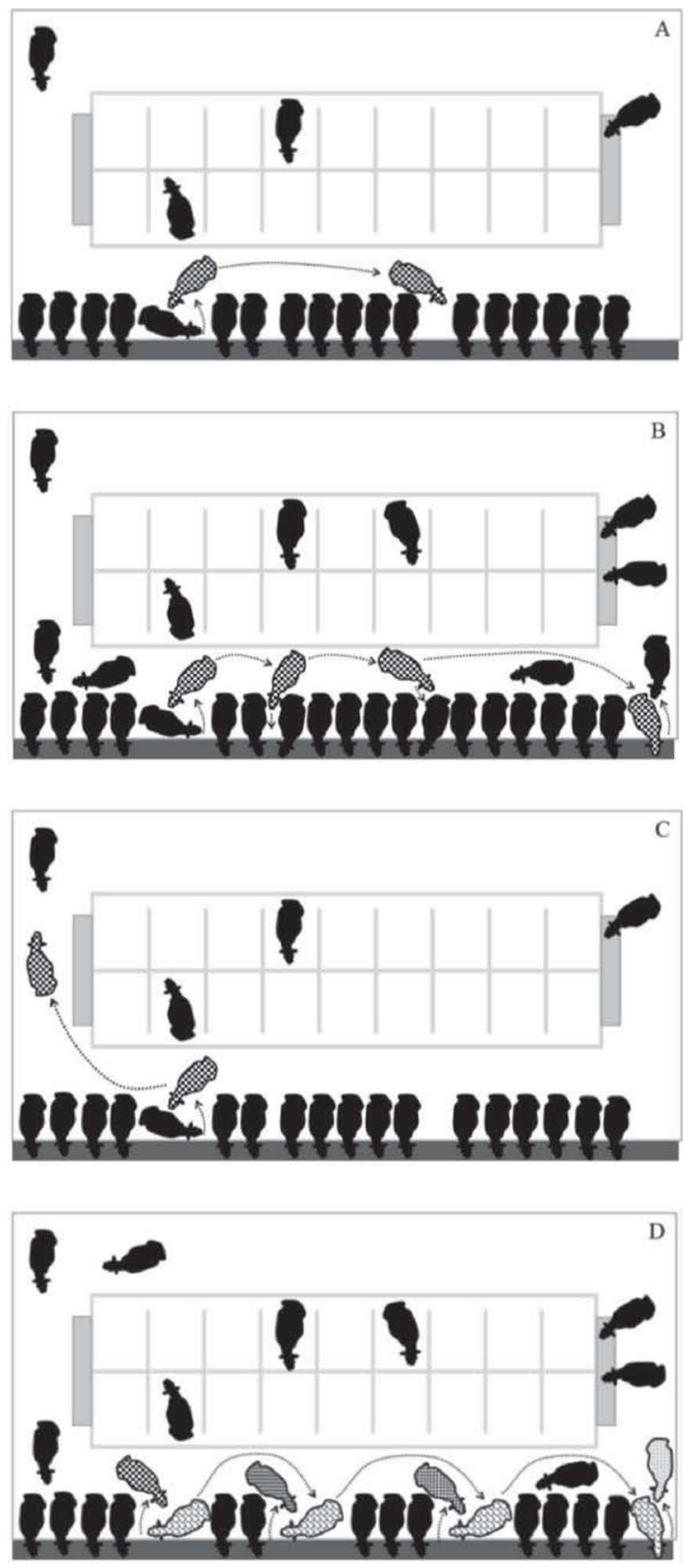

Figure 3. Possible fates of cows that face competition in the feed bunk according to management conditions and cow demeanor. (A) A submissive cow (checkerboard) reacts to a dominant cow, displacing the submissive cow from the feed bunk. However, the submissive cow is able to feed elsewhere in the pen because stocking density is $\leq 100 \%$. (B) A submissive cow (checkerboard) reacts to a dominant cow, displacing the submissive cow from the feed bunk. Although stocking density is approximately $135 \%$, the submissive cow that has an aggressive demeanor reaches the feed bunk after 2 attempts to displace other cows. (C) A submissive cow (checkerboard) reacts to a dominant cow, displacing the submissive cow from the feed bunk. Although stocking density is $\leq 100 \%$, the submissive cow has a less aggressive demeanor and does not attempt to feed to avoid new confrontations. (D) A dominant cow (shingle board) displaces several submissive cows from the feed bunk before establishing herself at the feedbunk and eating, but it may forego time feeding to establish its dominance over several of its pen mates. 
tinuously fight for resources. In Figure 3, we provide a graphic depiction of what we believe are possible fates of dominant and subordinate cows according to their interactions with pen mates and their resilience to continue to seek resources (e.g., feed). For example, highly dominant animals that are frequently involved in agonistic behavior may forego DMI, water consumption, and resting time to prevent their pen mates from gaining access to these resources (Figure 3). A cow that loses interactions at the feed bunk, however, may not suffer negative health consequences if it continues to fight for resources independent of stocking density (Figure 3). On the other hand, a cow that loses interactions at the feed bunk and does not fight for resources would benefit from reduced stocking density, but it would have higher risk of health disorders independent of management conditions (Figure 3). Although it may seem logical to suggest that dominant and subordinate animals should be housed separately, a few issues arise from such conclusion. First, when animals are regrouped according to social rank, a new social ranking is established, creating a revolving door scenario. Second, it is impractical in modern dairy operations to infinitely reduce group sizes to prevent antagonistic interactions among cows. Complete cessation of antagonistic behavior would only be possible in a tie stall dairy. Providing sufficient access to feed, water, and resting space is critical to reduce the consequences of social dominance on immune function, health, and performance.

\section{CONCLUSIONS}

Our understanding of the behavioral responses of dairy cows to social stressors has improved dramatically in the past decade. Nonetheless, much is still unknown regarding the consequences of social stressors on immune and neuroendocrine responses of dairy cows. Evaluation of stress responses of dairy cows using more holistic approaches may elucidate whether there are links among behavioral responses, immune and metabolic status, and biological function. Future efforts to evaluate management strategies that mitigate social stress among periparturient dairy cows must focus on behavioral, immune, and neuroendocrine responses as well as biological function of the animals to ascertain that recommendations indeed have an effect on animal well-being and sustainability of dairy herds. Proper management (easy access to feed, water, and resting space; heat stress abatement; strategies to reduce likelihood of hypocalcemia) supersedes the importance of minimizing regrouping and reducing stocking density, particularly in the prepartum period.

\section{ACKNOWLEDGMENTS}

Experiments conducted by the authors described herein were partially funded by the Minnesota Agricultural Experiment Station through Rapid Agriculture Response Fund grant (Saint Paul, MN).

\section{REFERENCES}

Abade, C. C., J. A. Fregonesi, M. A. von Keyserlingk, and D. M. Weary. 2015. Dairy cow preference and usage of an alternative freestall design. J. Dairy Sci. 98:960-965.

Arave, C. W., and J. L. Albright. 1976. Social rank and physiological traits of dairy cows as influenced by changing group membership. J. Dairy Sci. 59:974-981.

Aubert, A. 1999. Sickness and behaviour in animals: A motivational perspective. Neurosci. Biobehav. Rev. 23:1029-1036.

Bewley, J., R. W. Palmer, and D. B. Jackson-Smith. 2001. An overview of experiences of Wisconsin dairy farmers who modernized their operations. J. Dairy Sci. 84:717-729.

Caroprese, M., G. Annicchiarico, L. Schena, A. Muscio, R. Migliore, and A. Sevi. 2009. Influence of space allowance and housing conditions on the welfare, immune response and production performance of dairy ewes. J. Dairy Res. 76:66-73.

Cook, N. B. 2002. The influence of barn design on dairy cow hygiene, lameness, and udder health. Pages 97-103 in Proc. 35th Annu. Conf. Am. Assoc. Bovine Pract., Stillwater, OK.

Coonen, J. M., M. J. Maroney, P. M. Crump, and R. R. Grummer. 2011. Short communication: Effect of a stable pen management strategy for precalving cows on dry matter intake, plasma nonesterified fatty acid levels, and milk productions. J. Dairy Sci. 94:2413-2417.

Deming, J. A., R. Bergeron, K. E. Leslie, and T. J. DeVries. 2013. Associations of housing, management, milking activity, and standing and lying behavior of dairy cows milked in automatic systems. J. Dairy Sci. 96:344-351.

DeVries, T. J., M. A. G. von Keyserlingk, and D. M. Weary. 2004. Effect of feeding space on the inter-cow distance, aggression, and feeding behavior of free-stall housed lactating dairy cows. J. Dairy Sci. 87:1432-1438.

DFC-NFACC. 2009. DFC-NFACC (Dairy Farmers of Canada and the National Farm Animal Care Council) Code of Practices for the Care and Handling of Dairy Cattle. Dairy Farmers of Canada, Ottawa, Ontario, Canada.

Ebbesen, P., J. A. Villadsen, D. Villadsen, and K. E. Heller. 1991. Effect of subordinate, lack of social hierarchy and restricted feeding on murine survival and virus leukemia. Exp. Gerontol. 26:479-486.

Elsasser, T. H., K. C. Klasing, N. Filipov, and F. Thompson. 2000. The metabolic consequences of stress: Targets for stress and priorities of nutrient use. Pages 77-110 in The Biology of Animal Stress: Basic Principles and Implications for Animal Welfare. 1st ed. CABI Publishing, New York, NY.

Fregonesi, J. A., C. B. Tucker, and D. M. Weary. 2007. Overstocking reduces lying time in dairy cows. J. Dairy Sci. 90:3349-3354

Friend, T. H., and C. E. Polan. 1974. Social rank, feeding behavior, and free stall utilization by dairy cattle. J. Dairy Sci. 57:1214-1220.

Galindo, F., and D. M. Broom. 2000. The relationships between social behavior of dairy cows and the occurrence of lameness in three herds. Res. Vet. Sci. 69:75-79.

Goff, J. P., and R. L. Horst. 1993. Oral administration of calcium salts for treatment of hypocalcemia in cattle. J. Dairy Sci. 76:101-108.

Goldhawk, C., N. Chapinal, D. M. Veira, D. M. Weary, and M. A. von Keyserlingk. 2009. Prepartum feeding behavior is an early indicator of subclinical ketosis. J. Dairy Sci. 92:4971-4977.

Grant, R. 2007. Taking advantage of natural behavior improves dairy cow performance. Pages 225-236 in Proc. Western Dairy Management Conf., Reno, NV. 
Grant, R. J., and J. L. Albright. 1995. Feeding behavior and management factors during the transition period in dairy cattle. J. Anim. Sci. $73: 2791-2803$

Grant, R. J., and J. L. Albright. 2001. Effect of animal grouping on feeding behavior and intake of dairy cattle. J. Dairy Sci. 84:E156E163.

Guard, C. 2002. Environmental risk factors contributing to lameness in dairy cattle. Pages 271-277 in Dairy Housing and Equipment Systems, Managing, and Planning for Profitability. Natural Resource, Agriculture, and Engineering Service Publ. 129. Camp Hill, PA.

Hammon, D. S., I. M. Evjen, T. R. Dhiman, J. P. Goff, and J. L. Walters. 2006. Neutrophil function and energy status in Holstein cows with uterine health disorders. Vet. Immunol. Immunopathol. 113:21-29.

Hansen, P. J. 2009. Effects of heat stress on mammalian reproduction. Philos. Trans. R. Soc. Lond. B Biol. Sci. 364:3341-3350.

Hasegawa, N., A. Nishiwaki, K. Sugawara, and I. Ito. 1997. The effects of social exchange between two groups of lactating primiparous heifers on milk production, dominance order, behavior and adrenocortical response. Appl. Anim. Behav. Sci. 51:15-27.

Haskell, M. J., G. Simm, and S. P. Turner. 2014. Genetic selection for temperament traits in dairy and beef cattle. Front. Genet. 5:368.

Hessing, M. J. C., C. J. M. Scheepens, W. G. P. Schouten, M. J. M. Tielen, and P. R. Wiepkema. 1994. Social rank and disease susceptibility in pigs. Vet. Immunol. Immunopathol. 43:373-387.

Hetti Arachchige, A. D., A. D. Fisher, W. J. Wales, M. J. Auldist, M. C. Hannah, and E. C. Jongman. 2014. Space allowance and barriers influence cow competition for mixed rations fed on a feed-pad between bouts of grazing. J. Dairy Sci. 97:3578-3588.

Hill, C. T., P. D. Krawczel, H. M. Dann, C. S. Ballard, R. C. Hovey, and R. J. Grant. 2009. Effect of stocking density on the short-term behavior of dairy cows. Appl. Anim. Behav. Sci. 117:144-149.

Hohenbrink, S., and S. Meinecke-Tillmann. 2012. Influence of social dominance on the secondary sex ratio and factors affecting hierarchy in Holstein dairy cows. J. Dairy Sci. 95:5694-5701.

Hosseinkhani, A., T. J. Devries, K. L. Proudfoot, R. Valizadeh, D. M. Veira, and M. A. von Keyserlingk. 2008. The effects of feed bunk competition on the feed sorting behavior of close-up dry cows. J. Dairy Sci. 91:1115-1121.

Hulbert, L. E., J. A. Carroll, N. C. Burdick, R. D. Randel, M. S. Brown, and M. A. Ballou. 2011. Innate immune responses of temperamental and calm cattle after transportation. Vet. Immunol. Immunopathol. 143:66-74.

Huzzey, J. M., T. J. DeVries, P. Valois, and M. A. von Keyserlingk 2006. Stocking density and feed barrier design affect the feeding and social behavior of dairy cattle. J. Dairy Sci. 89:126-133.

Huzzey, J. M., R. J. Grant, and T. R. Overton. 2012. Short communication: Relationship between competitive success during displacements at an overstocked feed bunk and measures of physiology and behavior in Holstein dairy cattle. J. Dairy Sci. 95:4434-4441.

Huzzey, J. M., D. M. Veira, D. M. Weary, and M. A. G. von Keyserlingk. 2007. Prepartum behavior and dry matter intake identify cows at risk for metritis. J. Dairy Sci. 90:3220-3233.

Kendall, P. E., P. P. Nielsen, J. R. Webster, G. A. Verkerk, R. P. Littlejohn, and L. R. Matthews. 2006. The effects of providing shade to lactating dairy cows in a temperate climate. Livest. Sci. 103:148-157.

Kondo, S., and J. F. Hurnik. 1990. Stabilization of social hierarchy in dairy cows. Appl. Anim. Behav. Sci. 27:287-297.

Krawczel, P. D., C. T. Hill, H. M. Dann, and R. J. Grant. 2008. Short communication: effect of stocking density on indices of cow comfort. J. Dairy Sci. 91:1903-1907.

Krawczel, P. D., L. B. Klaiber, R. E. Butzler, L. M. Klaiber, H. M. Dann, C. S. Mooney, and R. J. Grant. 2012. Short-term increases in stocking density affect the lying and social behavior, but not the productivity, of lactating Holstein dairy cows. J. Dairy Sci. 95:4298-4308.

Legrand, A. L., M. A. von Keyserlingk, and D. M. Weary. 2009. Preference and usage of pasture versus free-stall housing by lactating dairy cattle. J. Dairy Sci. 92:3651-3658.
Lobeck-Luchterhand, K. M. 2014. Effect of grouping strategy and stocking density on the behavior of prepartum dairy cows and the association between behavior and periparturient cow health. $\mathrm{PhD}$ Thesis. Department of Animal Sciences, University of Minnesota.

Lobeck-Luchterhand, K. M., P. R. Silva, R. C. Chebel, and M. I. Endres. 2015. Effect of stocking density on social, feeding, and lying behavior of prepartum dairy animals. J. Dairy Sci. 98:240-249

Lobeck-Luchterhand, K. M., P. R. B. Silva, R. C. Chebel, and M. I. Endres. 2014. Effect of prepartum grouping strategy on displacements from the feed bunk and feeding behavior of dairy cows. J. Dairy Sci. 97:2800-2807.

McEwen, B. S. 2000. The neurobiology of stress: From serendipity to clinical relevance. Brain Res. 886:172-189.

McEwen, B. S. 2008. Central effects of stress hormones in health and disease: Understanding the protective and damaging effects of stress and stress mediators. Eur. J. Pharmacol. 583:174-185.

Melia, M., M. Schmidt, B. Geissler, J. König, U. Krahn, H. J. Ottersbach, S. Letzel, and A. Muttray. 2015. Measuring mechanical pain: The refinement and standardization of pressure pain threshold measurements. Behav. Res. Methods 47:216-227.

Miltenburg, C. L. 2015. Management of peripartum dairy cows for metabolic health and immune function. Doctor in Veterinary Science in Population Medicine Thesis Dissertation, University of Guelph.

Moberg, G. P. 2000. Biological response to stress: Implications for animal welfare. Pages 1-22 in The Biology of Animal Stress: Basic Principles and Implications for Animal Welfare. 1st ed. CABI Publishing, New York, NY.

Munksgaard, L., and H. B. Simonsen. 1996. Behavioral and pituitary adrenal-axis responses of dairy cows to social isolation and deprivation of lying down. J. Anim. Sci. 74:769-778.

Nordlund, K., N. Cook, and G. Oetzel. 2006. Commingling dairy cows: Pen moves, stocking density, and health. Pages 36-42 in Proc. Am. Assoc. Bovine Pract., St. Paul, MN.

Oetzel, G. R., K. M. Emery, W. P. Kautz, and J. E. Nocek. 2007. Direct-fed microbial supplementation and health and performance of pre- and postpartum dairy cattle: A field trial. J. Dairy Sci. 90:2058-2068.

Olofsson, J. 1999. Competition for total mixed diets fed for ad libitum intake using one or four cows per feeding station. J. Dairy Sci. 82:69-79.

Patbandha, T. K., T. K. Mohanty, S. S. Layek, A. Kumaresan, and K. Behera. 2012. Applications of pre-partum feeding and social behavior in predicting risk of developing metritis in crossbred cows. Appl. Anim. Behav. Sci. 139:10-17.

Proudfoot, K. L., M. B. Jensen, D. M. Weary, and M. A. G. von Keyserlingk. 2014. Dairy cows seek isolation at calving and when ill. J. Dairy Sci. 97:2731-2739.

Proudfoot, K. L., D. M. Veira, D. M. Weary, and M. A. G. von Keyserlingk. 2009. Competition at the feed bunk changes the feeding, standing, and social behavior of transition dairy cows. J. Dairy Sci. 92:3116-3123.

Schirmann, K., N. Chapinal, D. M. Weary, W. Heuwieser, and M. A. G. von Keyserlingk. 2011. Short-term effects of regrouping on behavior of prepartum dairy cows. J. Dairy Sci. 94:2312-2319.

Silva, P. R., A. R. Dresch, K. S. Machado, J. G. Moraes, K. LobeckLuchterhand, T. K. Nishimura, M. A. Ferreira, M. I. Endres, and R. C. Chebel. 2014. Prepartum stocking density: Effects on metabolic, health, reproductive, and productive responses. J. Dairy Sci. 97:5521-5532.

Silva, P. R., J. G. Moraes, L. G. Mendonça, A. A. Scanavez, G. Nakagawa, M. A. Ballou, B. Walcheck, D. Haines, M. I. Endres, and R. C. Chebel. 2013b. Effects of weekly regrouping of prepartum dairy cows on innate immune response and antibody concentration. J. Dairy Sci. 96:7649-7657.

Silva, P. R. B., K. M. Lobeck-Luchterhand, R. L. A. Cerri, D. M. Haines, M. A. Ballou, M. I. Endres, and R. C. Chebel. 2016. Effects of prepartum stocking density on innate and adaptive leukocyte responses and serum and hair cortisol concentrations. Vet. Immunol. Immunopathol. 169:39-46. 
Silva, P. R. B., J. G. N. Moraes, L. G. D. Mendonça, A. A. Scanavez, G. Nakagawa, J. Fetrow, M. I. Endres, and R. C. Chebel. 2013a. Effects of weekly regrouping of prepartum dairy cows on metabolic, health, reproductive, and productive parameters. J. Dairy Sci. 96:4436-4446

Singh, S. S., W. R. Ward, K. Lautenbach, J. W. Hughes, and R. D. Murray. 1993. Behaviour of first lactation and adult dairy cows while housed and at pasture and its relationship with sole lesions. Vet. Rec. 133:469-474.

Sova, A. D., S. J. LeBlanc, B. W. McBride, and T. J. DeVries. 2013. Associations between herd-level feeding management practices, feed sorting, and milk production in freestall dairy farms. J. Dairy Sci. 96:4759-4770.

Stefanski, V., S. K. Hemschemeier, K. Schunke, A. Hahnel, C. Wolff, and R. H. Straub. 2013. Differential effect of severe and moderate social stress on blood immune and endocrine measures and susceptibility to collagen type II arthritis in male rats. Brain Behav. Immun. 29:156-165.
Stock, M. L., S. T. Millman, L. A. Barth, N. K. Van Engen, W. H. Hsu, C. Wang, R. Gehring, R. L. Parsons, and J. F. Coetzee. 2015. The effects of firocoxib on cautery disbudding pain and stress responses in preweaned dairy calves. J. Dairy Sci. 98:6058-6069.

Tuchscherer, M., B. Puppe, A. Tuchscherer, and E. Kanitz. 1998. Effects of social status after mixing on immune, metabolic, and endocrine responses in pigs. Physiol. Behav. 64:353-360.

Val-Laillet, D., D. M. Veira, and M. A. G. von Keyserlingk. 2008. Short communication: Dominance in free-stall housed dairy cattle is dependent on resource. J. Dairy Sci. 91:3922-3926.

von Keyserlingk, M. A. G., D. Olenick, and D. M. Weary. 2008. Acute behavioral effects of regrouping dairy cows. J. Dairy Sci. 91:10111016.

Wechsler, B. 2007. Normal behaviour as a basis for animal welfare assessment. Anim. Welf. 16:107-110 